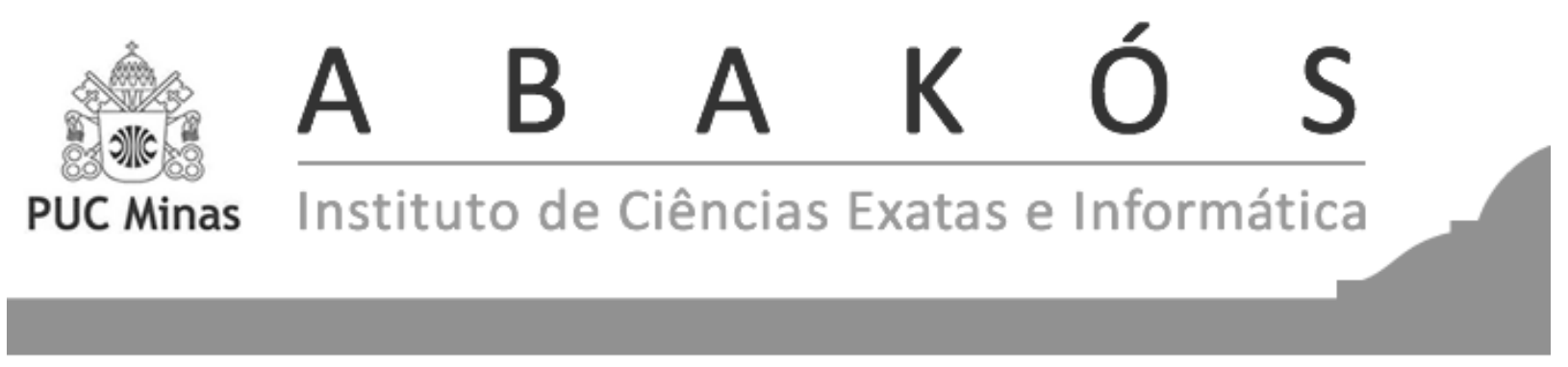

\title{
Videoanálise e Ensino de Física em Situação de Vulnerabilidade Social $^{*}$
}

Videoanalysis and Teaching of Physics in a Situation of Social Vulnerability

\author{
Fábio Anastácio de Oliveira ${ }^{1}$ \\ Jorge Alberto Lenz ${ }^{2}$ \\ Nestor Cortez Saavedra Filho ${ }^{3}$ \\ Arandi Ginane Bezerra Junior ${ }^{4}$
}

\begin{abstract}
Resumo
O presente trabalho apresenta uma aplicação em sala de aula do software livre Tracker, que é destinado à vídeoanálise, ou análise de movimentos quadro a quadro. A utilização do programa tem como objetivo criar alternativas para a falta de um efetivo laboratório didático de Ciências, falta que é um problema real em várias escolas brasileiras. Com a videoanálise, é possível abordar conceitos de Física por meio de filmagens feitas com câmeras digitais, inclusive aquelas presentes em telefones celulares. Os filmes podem ser gravados e analisados com o próprio Tracker ou com auxílio de um programa de planilhas eletrônicas. A proposta foi aplicada em turmas do $1^{\circ}$ ano do Ensino Médio em uma escola pública da rede estadual, que atende alunos de uma região carente e com grande risco social. A avaliação do trabalho foi realizada por meio de um relatório contendo questões sobre queda livre, comparando situações em que o programa foi usado com outras em que não foi. $\mathrm{O}$ material utilizado propôs aos alunos uma dinâmica motivadora para aprender e aplicar seus conhecimentos. Além disso, as aulas com o Tracker serviram de estímulo aos estudantes para um uso inclusivo e crítico de recursos tecnológicos.
\end{abstract}

Palavras-chave: Tracker. Laboratório de Física. Vídeoanálise.

\footnotetext{
* Submetido em 06/06/2018 - Aceito em 21/12/2018

${ }^{1}$ Universidade Tecnológica Federal do Paraná-UTFPR, Brasil- faooibaf@yahoo.com.br

${ }^{2}$ Universidade Tecnológica Federal do Paraná-UTFPR, Brasil- lenz@utfpr.edu.br

${ }^{3}$ Universidade Tecnológica Federal do Paraná-UTFPR, Brasil-nestorsf@utfpr.edu.br

${ }^{4}$ Universidade Tecnológica Federal do Paraná-UTFPR, Brasil- arandi@utfpr.edu.br
} 


\begin{abstract}
In this work, we present results of an activity involving videoanalysis, using the software Tracker, as an alternative tool to teach physics in high school. Our main goal is to provide alternatives to the lack of physics teaching laboratories, which is a major problem faced by many Brazilian schools. Videoanalysis is a powerful tool made possible by common digital cameras, including the ones present in mobile phones. Videos are recorded allowing for data collection and analysis with Tracker and any usual spreadsheet software. The project was tested with students attending the first year of a public high school. The school is located in a region characterized by poverty and social risk. Results were assessed by a report, elaborated by the students, consisting of questions related to the subject freefall, with and without the use of videoanalysis. The developed material offered students a different learning perspective, aiming at improving students' motivation towards learning Physics. The lectures involving experimental activities with Tracker were also an efficient way of stimulating critical thinking allied to the inclusive use of technology in the school environment.
\end{abstract}

Keywords: Tracker. Physics Laboratory. Videoanalysis. 


\section{INTRODUÇÃO}

Parte-se do pressuposto que o entendimento da natureza da Ciência, em especial da Física, constitui um importante elemento para a formação de cidadãos conscientes e críticos. Nesse sentido, além da formação baseada em conteúdos específicos, o processo educativo também deve capacitar os indivíduos a compreender os avanços tecnológicos atuais, o que torna necessário, ainda, formar professores para o uso de mediações tecnológicas no ensino e aprendizagem (AVIDOV-UNGAR; FORKOSH-BARUCH, 2018). Assim, os professores tornam-se agentes no despertar e no reforço das condições para que os estudantes, por sua vez, atuem de modo fundamentado nos grupos sociais em que convivem. Uma forma de atingir esses objetivos consiste no desenvolvimento de atividades escolares que combinem aulas de laboratório e atividades investigativas, enquanto instrumentos valiosos para refletir sobre o próprio trabalho em sala de aula, e ousar "aulas diferentes" como forma alternativa de ensinar Física (MÜTZENBERG, 2005). Esse processo tende a possibilitar melhor desenvolvimento do conteúdo, por parte do professor, e despertar maior interesse e curiosidade, por parte dos alunos (e também do professor), além de uma componente afetiva importante, de modo a proporcionar uma atmosfera mais aberta e colaborativa.

Assim, busca-se potencializar situações e relações permanentes dos estudantes com o seu mundo, no que, segundo Freire (2011), permite atos de criação e recriação, pela interação entre esses estudantes e os objetos de estudo. Isso implica em gerar conhecimento, expresso através da cultura como aquisição sistemática da experiência humana e não como uma justaposição de informações ou prescrições impostas. Entretanto, essa visão emancipatória, em que há aprendizagem do conhecimento como construção cultural, esbarra em estratificações da sociedade, bem como em delimitações espaciais de território, no que a vulnerabilidade social se faz presente.

A vulnerabilidade social é conceituada por Miriam Abramovay e colaboradores (2002) como situações em que os recursos e habilidades de um grupo social são insuficientes e inadequados para lidar com as oportunidades que a própria sociedade oferece, ou seja:

A vulnerabilidade social é tratada aqui como o resultado negativo da relação entre a disponibilidade dos recursos materiais ou simbólicos dos atores, sejam eles indivíduos ou grupos, e o acesso à estrutura de oportunidades sociais, econômicas, culturais que provêm do Estado, do mercado e da sociedade. Esse resultado se traduz em debilidades ou desvantagens para o desempenho e mobilidade social dos atores (ABRAMOVAY et al., 2002).

Uma das soluções para superação dessa vulnerabilidade social seria por intermédio de uma educação política, emancipatória e transformadora (PEDRINI et al., 2010). Além disto, é necessário trabalhar a respeito da menor disponibilidade de recursos materiais (contornada, nesta proposta, pelo uso da videoanálise) ou simbólicos (a mediação do conhecimento físico como construto de caráter experimental), dimensões latentes na formação do professor do Sé- 
culo XXI (AVIDOV-UNGAR; FORKOSH-BARUCH, 2018). Entretanto, num recorte das políticas educacionais dispostas para os estratos da sociedade que fazem uso das redes públicas, em suas diversas esferas - embora sempre se coloquem a inclusão e possibilidades aos indivíduos como eixo norteador -, nota-se que, nas escolas públicas, as condições materiais e de formação profissional não são exatamente aquelas expressas no Plano Nacional de Educação (BRASIL, 2014). Isso termina por restringir as oportunidades para a citada mobilidade social dos estudantes das comunidades menos assistidas, configurando, portanto, na vulnerabilidade social dos mesmos. Num âmbito regional, percebe-se, dentro desse contexto, uma série de deficiências e demandas por parte de professores e alunos da Rede Pública do Paraná com respeito ao processo de ensino e aprendizagem de Ciências Naturais, particularmente a Física (STORI et al., 2009). Por exemplo, muitas escolas que oferecem Ensino Médio, não têm um laboratório de Ciências adequado para a realização de atividades demonstrativas e experimentos, implicando em um ensino empobrecido baseado principalmente em quadro negro e giz. Por outro lado, é fato que grande parte dos colégios públicos do Paraná possui um laboratório de informática. Daí a ideia de utilizar a videoanálise nas aulas de Física, porque essa permite a realização de atividades de laboratório mediadas por computador, encetando múltiplas configurações das salas de aula e das dinâmicas de interação aluno-professor-escola, interações com o condão de produzir espaços de criação e de exercício de autonomia. Portanto, a proposta deste trabalho consiste no uso do programa Tracker como ferramenta para videoanálise, enquanto alternativa para minimizar o problema da ausência de laboratórios de Ciências e, além disso, oferecer aos alunos contato com recursos tecnológicos e diferentes metodologias de ensino relacionadas à Física. Tem-se aqui, portanto, uma interação entre os estudantes e os temas de estudo, para produção do conhecimento, em que a mediação do processo de ensino e aprendizagem por uma tecnologia da informação e comunicação (TIC), a videoanálise, pode suprir, mesmo que parcialmente, a falta de laboratórios didáticos nas escolas públicas, agindo, portanto, como um instrumento para aumentar as oportunidades de aprendizagem, bem como tornar os alunos fluentes em mediações tecnológicas que vão além da corrente utilização de mídias sociais, outrossim, proporcionar a eles, através desta fluência, oportunidades de observar a natureza, coletar e analisar dados, como parte da compreensão de sua realidade. Esse processo enseja elementos de modernização da escola e da sala de aula, bem como uma valorização do espaço escolar público. Assim que as aulas de Física fomentam novidade referenciada, interação crítica e mesmo o desenvolvimento de autoestima, instrumentos para redução e superação da vulnerabilidade social. Tendo em vista a situação exposta, a contribuição do presente trabalho é norteada pelos seguintes objetivos:

- Investigar, estudar, por em prática e divulgar o uso de tecnologias livres e acessíveis ao Ensino de Física na Rede Pública, em especial a videoanálise com o programa Tracker;

- Analisar se o uso do programa Tracker nas aulas de Física do primeiro ano do Ensino Médio pode ser útil, enquanto ferramenta do professor, e se possibilita a realização de experimentos, por parte dos alunos, na situação de ausência de laboratório formal de Ciências/Física; 
- Despertar nos estudantes do Ensino Médio o interesse pela pesquisa científica e pela observação da natureza com olhar crítico e incentivar o gosto pelo estudo, contribuindo para a valorização da escola.

\section{LABORATÓRIO DIDÁTICO E EXPERIMENTAÇÃO NO ENSINO DE FÍSICA}

Segundo Pinho Alves (2004) a Física sempre esteve muito ligada aos procedimentos e práticas experimentais, tendo uma relação bastante estreita com atividades de laboratório. Portanto, essas também são elemento importante e necessário para aprender Física. Nesse sentido, trata-se de relacionar o laboratório didático com o processo de transposição didática, o qual visa a adaptar elementos do saber sábio (aquele produzido e elaborado pelos cientistas) para o contexto do saber a ensinar (aquele a ser levado para a sala de aula).

Para Araújo (2003), as atividades de experimentação partem de situações que estimulam os alunos a refletir e (re)elaborar suas ideias para que sejam capazes de (re)estruturar seus modelos mentais. Esse processo visa ao entendimento e explicação dos fenômenos físicos por meio da utilização de ferramentas e conceitos científicos mais elaborados. De fato, importa anotar diferenças entre experiência e experimentação: a primeira tem a ver com uma interação imediata do ser humano com seu meio ambiente, a qual gera explicações prévias do mundo que não são rompidas facilmente (PINHO, 2000), e que interferem no aprendizado ao fornecer um substrato intelectual para novos conhecimentos (BORGES, 2002); a experimentação, por sua vez, é uma atividade metódica estruturada e elaborada visando à construção do conhecimento científico. Nesse sentido, o uso do laboratório didático pode ser combinado a estratégias de apresentação, organização e problematização do pensamento científico.

Dentre os diversos modelos de laboratório didático, que favorecem a experimentação, destacamos o Laboratório Divergente ou Não-Estruturado (PINHO, 2004), o qual possibilita ao aluno trabalhar com procedimentos físicos reais ("agir como cientista"), oportunizando a resolução de problemas abertos, com respostas desconhecidas pelo aluno, em contraste com o Laboratório Tradicional, esse associado à aprendizagem mecânica e acrítica. No processo da experimentação, também se busca familiarizar os alunos com equipamentos experimentais e técnicas de medida, visando à construção/elaboração dos conceitos científicos. No caso específico do trabalho aqui apresentado, foram elaboradas atividades de Laboratório Divergente por meio da videoanálise com o software Tracker. Defende-se que a videoanálise constitui tecnologia portadora de potencial para incentivar os estudantes a terem um papel de protagonistas no processo de ensino-aprendizagem, ademais ampliando o leque de opções de intervenção em sala de aula por parte do professor. Além disso, também permite versar os alunos no uso das TIC, com implicações na ampliação de sua cidadania e consequente diminuição de sua vulnerabilidade social. 


\section{TECNOLOGIAS DE INFORMAÇÃO E COMUNICAÇÃO (TIC) EM SALA DE AULA}

De acordo com Vicente (2005), a tecnologia atual é poderosa a ponto de mudar as relações sociais, de trabalho e estudo, no entanto, é preciso também conhecer as consequências resultantes de um foco voltado exclusivamente para os detalhes técnicos. Consequentemente, para que haja educação crítica, é necessário combinar tecnologia e reflexão visando a despertar uma consciência da possibilidade de mudança (e de transformação do mundo) por meio dos diferentes aparatos ou construtos, inclusive tecnológicos, fruto da inventividade e trabalho humanos (FREIRE, 1987). Isso contrasta com o fato de que boa parte dos estudantes não têm a oportunidade de acesso a laboratórios de Ciências e, na maioria das escolas, as aulas práticas não acontecem pela não existência do laboratório (BORGES, 2002; BEZERRA et al., 2009). Se por um lado esta ausência representa menos contato com a tecnologia, deve-se buscar alternativas para superá-la. Daí a importância da utilização das TIC's no laboratório didático de Física, as quais dão destaque para o computador e seu potencial de uso, por exemplo, para a aquisição e análise de dados em atividades experimentais voltadas ao ensino. Por meio delas e a Videoanálise constitui poderoso exemplo - o computador ganha dimensão de uso e utilidade prática, servindo de veículo para a desmistificação, para ampliar a compreensão e para estender a apropriação da tecnologia, o que ganha contornos mais significativos no caso do processo ocorrer em escolas localizadas em áreas de vulnerabilidade social.

Para Veit (2005), o uso do computador propicia o enriquecimento da aprendizagem por oferecer aos professores e alunos múltiplas ferramentas que facilitam o entendimento dos temas estudados, com destaque, nas aulas de laboratório de Física, para as possibilidades na coleta de dados. Também Nesse contexto, a videoanálise constitui importante ferramenta (LENZ et al., 2014).

A vídeoanálise é um processo que consiste em filmar experimentos que envolvem o movimento, para depois analisá-los quadro a quadro, numa dinâmica que integra TIC e atividades de experimentação no laboratório. Além disso, trata-se de uma boa alternativa aos sistemas geralmente empregados em laboratórios, do tipo fotogate que, em geral, demandam circuitos eletrônicos contendo muitos fios e conectores que, por isso, podem ser inconvenientes em atividades didáticas, principalmente quando se leva em conta o tempo didático das aulas no Ensino Médio (BEZERRA et al., 2012). Atualmente, uma alternativa que tem sido amplamente utilizada para a realização de videoanálise é baseada no programa livre Tracker (TRACKER, 2018; TRACKERBRASIL, 2018). Dentre aplicações desse software, pode-se citar sua utilização em experimentos que envolvem a observação de fenômenos que ocorrem em curto intervalo de tempo, portanto, de difícil observação em um laboratório didático, como a verificação da relação entre o impulso e a variação de quantidade de movimento de um móvel numa colisão (WRASSE et al., 2014). Além disso, na observação de fenômenos em que haja dificuldades na distinção entre a trajetória de um objeto e a representação gráfica das grandezas físicas associadas (ARAUJO et al., 2004), a videoanálise também pode ser uma ferramenta útil, conforme ilustra um exemplo do estudo das relações entre movimento harmônico simples e movimento 
circular uniforme (SILVA, 2018). Também é possível, com a videoanálise mediada pelo Trac$k e r$, o estudo de movimentos aparentemente simples, mas que encerram sutilezas interessantes do ponto de vista da análise física como, por exemplo, o rolamento de cilindros em planos inclinados (PHOMMARACH et al., 2012) e também aplicações em Hidrodinâmica (SILVA; LIMA, 2017), essas duas últimas passíveis de serem transpostas ao Ensino Médio através da videonálise. Em todos esses trabalhos, são enaltecidas características como a observação, em tempo real, da evolução temporal das grandezas físicas e a sua representação em tabelas de dados e gráficos, passíveis de serem exportados do software e serem tratados em planilhas eletrônicas.

\section{VIDEOANÁLISE E O SOFTWARE TRACKER}

O Tracker é um software gratuito, de código aberto, que funciona em qualquer sistema operacional, e que está em constante desenvolvimento pela parceria entre a equipe comandada pelo professor D. Brown, do Cabrillo College (Estados Unidos) e pelo Open Source Physics ${ }^{5}$, que objetiva difundir o uso de ferramentas e bibliotecas de código aberto para o ensino de Física, baseadas em modelagem pelo uso do computador.

Segundo Bezerra Junior et al (2012) seu uso permite realizar a análise de vídeos (videoanálise), quadro a quadro, gravados com câmeras digitais, webcams de computadores comuns e telefones celulares, com a vantagem de não exigir um grande número de cabos e circuitos eletrônicos além de permitir obter uma quantidade maior de dados experimentais. Com o Tracker, pode-se rastrear objetos fornecendo a posição, velocidade e aceleração. O programa também permite gerar gráficos e realizar cálculos e operações que visam a uma análise pormenorizada do movimento de um (ou mais) corpo(s).

O programa Tracker pode ser obtido gratuitamente no sítio oficial na internet (TRACKER, 2018). Existem diversos recursos, tais como tutoriais, disponibilizados pelo grupo de pesquisa dos autores (TRACKERBRASIL, 2018), que é pioneiro na divulgação do uso do software em ambiente escolar brasileiro, sendo também responsável por sua versão em língua portuguesa.

O uso do Tracker cumpre várias funções no processo de ensino-aprendizagem, possibilitando que os alunos acompanhem a evolução de grandezas físicas em detalhes, quadro a quadro, para a coleta de dados e a construção de gráficos, permitindo o desenvolvimento de atividades investigativas e roteiros abertos compatíveis com as aulas e ambientes das escolas brasileiras (BEZERRA et al., 2012; LENZ et al., 2014; SAAVEDRA et al., 2017).

Dada a realidade do baixo número de aulas semanais de Física nas escolas, juntamente com a já mencionada inexistência ou sucateamento de laboratórios de Ciências, fica ainda mais evidente a importância do desenvolvimento e inserção de novas tecnologias educacionais. Nesse contexto, as tecnologias livres desempenham papel central (BEZERRA et al., 2009) e despontam como suporte ao laboratório e como instrumento para a modelagem científica (VEIT et

${ }^{5} \mathrm{http}: / /$ www.compadre.org/osp/ 
al., 2005; SAAVEDRA et al., 2017). É sob esse ponto de vista que surge a ideia de utilizar o Tracker como TIC mediadora de aulas de laboratório de Física (LENZ et al., 2014). Assim, a presente proposta visa a criar alternativas para que o experimento receba o tratamento adequado às componentes curriculares das aulas de Física do Ensino Médio, abrindo possibilidades múltiplas para abordar conceitos fundamentais da Física, tais como: velocidade, aceleração (SAAVEDRA et al., 2016), forças, viscosidade, eletrostática e a quantização da carga elétrica (BEZERRA et al., 2015). Além dos citados, também são criadas condições para discutir aspectos ligados à história da ciência e ao papel da Física Experimental, a compreensão de suas sutilezas procedimentais e o seu importante papel na construção do conhecimento físico.

Um experimento padrão mediado pelo Tracker consiste em gravar um vídeo de algum movimento de interesse. O vídeo deve, obrigatoriamente, conter um padrão de referência de distância (por exemplo, uma régua graduada). Na sequência, o arquivo de vídeo é transferido para um computador com o software previamente instalado, para que seja feita a marcação dos pontos quadro a quadro. O Tracker associa aos pontos de posição àqueles referentes ao tempo, ficando, então, disponíveis conjuntos de dados (x versus t) que podem ser analisados com o próprio Tracker ou por meio de um programa de planilhas eletrônicas. De acordo com a experiência dos autores, que inclui o uso do Tracker em aulas de Física em disciplinas de graduação (Engenharia e Física), pós-graduação (mestrado profissional em Ensino) e ensino médio, a videoanálise constitui tecnologia de fácil aprendizado, tanto por parte de professores quanto estudantes, e que pode ser incorporada às aulas de Física após algumas horas de estudo e de contato com o programa. Além disso, é crescente o número de artigos em que são apresentadas novas metodologias e atividades experimentais mediadas por videoanálise, especialmente o Tracker, de modo que há uma comunidade em expansão a dar instrução e apoio às iniciativas de utilizar tal tecnologia em sala de aula (BROWN; COX, 2009; BRYAN, 2010; PHOMMARACH et al., 2012; BEZERRA et al., 2012; SIRISATHITKUL et al., 2013; WRASSE et al., 2014; SILVA; LIMA, 2017; BONATO et al., 2017; SILVA, 2018). Essa, certamente, é uma característica que favorece sua apropriação por parte dos professores e que torna viável seu emprego na sala de aula.

\section{METODOLOGIA}

\subsection{Proposta de Intervenção Didática na Escola. Uso do Tracker no Primeiro Ano do En- sino Médio}

O trabalho de intervenção em sala de aula foi realizado em um Colégio Estadual de médio porte, localizado em Curitiba, em um dos cinco bairros onde, segundo a Secretaria de Estado da Segurança Pública (SESP) ocorreram 60\% dos crimes de assassinato na cidade (dados de 2008). Essa realidade tem relação, por exemplo, com o fato de que regularmente a rotina da escola era alterada por "toques de recolher" ditados por grupos criminosos, o que afeta conside- 
ravelmente a participação dos alunos, o andamento das aulas e o rendimento escolar. O projeto em tela envolveu 131 alunos, divididos em cinco turmas regulares do $1^{\circ}$ ano do Ensino Médio. Essas turmas contam com alunos em condições socioeconômicas bem diversificadas e a escola não possui laboratório didático de Física. Assim, foi possível a utilização do laboratório de informática e do programa Tracker para atividades experimentais mediadas pela videoanálise.

$\mathrm{Na}$ primeira parte do trabalho, optou-se por abordar o tópico curricular Queda Livre, que consiste no estudo da queda dos corpos na superfície terrestre. Todas as atividades foram planejadas seguindo os conteúdos programados para o $1^{\circ}$ ano do Ensino Médio. O tópico escolhido encaixa-se no conteúdo estruturante de Movimento, presente nas Diretrizes Curriculares Estaduais do Paraná (DCE), para a disciplina de Física (PARANÁ, 2018).

Foram elaboradas aulas com enfoque interdisciplinar, abordando conteúdos de Física, Filosofia e História. Foi determinado o caráter acelerado do movimento, que é retilíneo e uniformemente variado (MRUV), e o valor da aceleração da gravidade $(g)$. Também foi discutido o método científico, inspirado pelos trabalhos de Galileu. A ideia era despertar reflexões sobre os experimentos, pois, segundo GERALDO (2009), um trabalho assim contextualizado possibilita a aplicação da interdisciplinaridade, além de despertar uma visão mais abrangente do processo científico.

$\mathrm{O}$ andamento da intervenção didática foi avaliado por meio de relatórios elaborados pelos estudantes e, no transcorrer das atividades, o professor manteve um diário de campo a fim de anotar elementos considerados importantes durante as aulas. O conjunto dos materiais foi posteriormente analisado, configurando abordagem de pesquisa qualitativa de cunho interpretativo. Destaca-se que os relatórios constituem o principal instrumento de análise de dados (a serem apresentados na seção de resultados) e foram propostos tendo em vista aproximar os estudantes dos formatos de escrita científica. Nesse sentido, o professor propôs uma estrutura formada por: título, introdução, desenvolvimento experimental, resultados, discussão/conclusão. Na oportunidade, o professor também apresentou aos alunos alguns modelos de artigos a fim de ilustrar a proposta.

\subsection{Sequência de Atividades}

Inicialmente, todas as equações do MRUV foram ensinadas pelo processo convencional, com quadro, giz e a realização de exercícios teóricos. O conteúdo de queda livre foi abordado em seguida, destacando-se que o valor da aceleração da gravidade na Terra é aproximadamente $9,81 \mathrm{~m} / \mathrm{s}^{2}$.

Após essa etapa, os alunos receberam uma lista de exercícios a fim de se prepararem para uma prova escrita, realizada ao fim de duas semanas. A nota mínima para ser considerada azul (desempenho regimentalmente satisfatório) correspondia a 60\%. No exame, o desempenho dos alunos se manteve como de costume, dada a série histórica do professor, quando aproximadamente dois terços da turma obtiveram notas azuis. Até esse momento, a intervenção foi 
equivalente às aulas tradicionalmente ministradas na disciplina e, a partir de então, foram introduzidas as atividades experimentais.

$\mathrm{Na}$ segunda etapa das atividades, foi pedido aos alunos que trouxessem cronômetros, podendo ser de relógios convencionais ou aparelhos de telefone celular. Essa nova etapa consiste no Procedimento 1.

\section{Procedimento 1 - Experimento com medição manual}

Para muitos alunos, essa foi a primeira vez que realizaram um experimento de Física. Esse foi integralmente feito em sala de aula.

Na primeira etapa do trabalho, as turmas foram divididas em equipes de três alunos. Em sala, uma bola foi abandonada cinco vezes das alturas de $2 m$ e de $2,5 \mathrm{~m}$. Utilizando os cronômetros de acionamento manual, as equipes deveriam marcar os tempos de queda, calcular uma média e, com esse valor, determinar o valor da aceleração da gravidade local $(g)$ usualmente considerado como sendo $9,81 \mathrm{~m} / \mathrm{s}^{2}$. Note-se que é comum, ao resolver exercícios no nível médio, aproximar $g$ como sendo $10 \mathrm{~m} / \mathrm{s}^{2}$, portanto, pretendia-se estimular os estudantes a obterem eles mesmos o valor de $g$, a fim de que pudessem dar mais significado ao que seria "apenas um número". Estabeleceu-se, após discussão, um erro experimental tolerado de 10\%; o objetivo seria determinar a "qualidade" dos resultados obtidos nos experimentos. Durante a realização das atividades em sala, foram levantadas questões para fazer os alunos refletirem sobre o que torna um experimento confiável. O professor explicou, por exemplo, que um erro experimental acima de $10 \%$ não significaria uma "falha" ou "fracasso" dos estudantes, assim que, ao realizar os experimentos, os alunos não estariam competindo entre si. A ideia seria, justamente, realizar os experimentos com o maior rigor possível, dadas as condições objetivas.

Após esse momento, no que pode ser considerada a segunda etapa, houve uma comparação entre os valores de tempo encontrados para os experimentos de queda livre obtidos na atividade experimental realizada pelos diversos colegas de sala. Em geral, as medições manuais com cronômetro resultam em resultados imprecisos e diferentes do valor padrão. Seguiu-se discussão na qual os estudantes puderam perceber que os grandes desvios dos resultados experimentais estariam associados à metodologia utilizada, incluindo instrumentos de medida (não é tarefa simples medir o tempo de queda de um objeto que cai a partir de uma altura de $2 \mathrm{~m}$ ). Destarte, uma tecnologia mais avançada poderia servir de meio para realizar experimentos mais elaborados e obter resultados mais precisos. Para finalizar o experimento 1 foram propostas três questões às equipes, de modo a consolidarem os resultados dos experimentos e as respectivas discussões: Questão 1: As duas experiências permitem obter valores próximos para $g$ ? Questão 2: Foi relativamente fácil acionar e parar o cronômetro nos exatos momentos que a bola inicia a queda e toca o solo? Questão 3: Qual foi o erro percentual em relação a $g$ encontrado nesse procedimento?

Na terceira etapa do trabalho, o Tracker foi apresentado aos alunos para a realização do Procedimento 2. A ideia era demonstrar como o uso do Tracker tornaria o experimento mais 
preciso e as medidas mais confiáveis. Com isto também se desperta nos estudantes um melhor entendimento a respeito do uso da tecnologia e da importância de sua apropriação.

\section{Procedimento 2 - Experimento com o Tracker}

O Tracker e suas funções básicas foram apresentados enfatizando-se os itens básicos para sua utilização. Como complemento para auxiliar os alunos na utilização do Tracker, também foi elaborado um vídeo e disponibilizado no Youtube ${ }^{6}$, oferecendo uma explicação sobre o programa e sobre como fazer o experimento de queda livre. As equipes de três alunos foram mantidas e, então, realizaram o experimento de queda livre assistido pelo Tracker. Nessa etapa, foi adotada a metodologia do laboratório não-estruturado (PINHO ALVES, 2004), no qual o professor solicitava aos alunos que encontrassem, de forma experimental e com o uso da videoanálise, um valor mais preciso de $g$, sem fazer uso de roteiros ou instruções pré-concebidas. Nesse processo, o professor esteve à disposição dos alunos para colaborar na solução de problemas operacionais e de como usar o programa. Interessantemente, todos os alunos participantes solicitaram o professor em diversos momentos - constituindo importante indicação de que o uso da videoanálise induz ao debate e à interação aluno-aluno e professor-aluno. Da mesma forma que no procedimento manual, as discussões finalizaram com a solicitação, pelo professor, para as equipes consolidarem respostas às seguintes perguntas: Qual foi o valor da aceleração encontrada usando o software Tracker? Os resultados encontrados usando o Tracker foram diferentes dos resultados encontrados no Procedimento 1? A aceleração usando o Tracker deu um valor próximo a $9,8 \mathrm{~m} / \mathrm{s}^{2}$ ? Qual foi o erro percentual?

Os resultados obtidos nesta etapa serão apresentados na próxima seção, que tem por objetivo uma exposição mais detalhada e uma discussão mais criteriosa sobre o uso do Tracker em sala de aula.

\section{RESULTADOS}

Ao final das atividades, cada equipe elaborou um relatório sobre os experimentos, seguindo um modelo simplificado (vide seção 5.1), semelhante a um artigo científico. Nesse relatório, além da descrição dos trabalhos realizados, foram respondidas as seis questões (conforme apresentado na seção anterior), referentes aos Procedimentos 1 e 2 da atividade proposta. Assim, o conjunto dos relatórios permitiu comparar elementos importantes no estudo da queda livre realizado com e sem o auxílio da videoanálise.

É interessante registrar que, ao longo do projeto, alguns alunos tiveram uma participação fundamental, ajudando os demais colegas a realizar e a interpretar os experimentos. Além disso, eles também colaboraram com a organização e manutenção dos materiais e equipamentos utilizados nos experimentos.

\footnotetext{
${ }^{6} \mathrm{https}: / / \mathrm{www} \cdot$ youtube.com/watch?v=9ZkRpgaqYFY
} 
Para demonstrar a taxa de sucesso das turmas nos trabalhos realizados, foram montados gráficos para comparar a eficiência dos dois procedimentos em cada turma e para mostrar os dados coletados em todas as turmas conjuntamente.

Para as duas etapas (experimento realizado com cronômetros e experimento realizado com o Tracker), foram elaborados gráficos com base nos seguintes critérios:

$\rightarrow$ Grupos que obtiveram $g$ dentro da tolerância de 10\%;

$\rightarrow$ Grupos que obtiveram $g$ fora da tolerância de $10 \%$;

$\rightarrow$ Grupos que não entregaram os trabalhos.

\section{DISCUSSÃO DOS RESULTADOS}

No gráfico da Figura 1 são compilados os resultados obtidos a partir dos relatórios entregues por todas as turmas, incluindo os 131 alunos para os quais o projeto foi aplicado e no gráfico da figura 2 os resultados obtidos, considerando todas as turmas, após a utilização do Tracker. Fica evidente que, no Procedimento 1 (medição manual com cronômetro), foi pequena (18\% do total) a quantidade de equipes capazes de determinar $g$ dentro da margem de tolerância estipulada. Por outro lado, com o uso do Tracker, houve um aumento significativo (para 56\%) no número de equipes que conseguiu realizar uma medição mais precisa, dentro da margem de tolerância estipulada. Além disso, também merece destaque o fato de que a taxa de alunos que não realizaram o trabalho diminuiu (de 26\% para 16\%) quando o Tracker foi empregado, o que pode ser interpretado como um estímulo à efetiva realização do trabalho, proporcionado pelo uso de TIC (a videoanálise).

Figura 1 - Resultados obtidos considerando todas as turmas, segundo o Procedimento 1 (medição manual, com cronômetro)

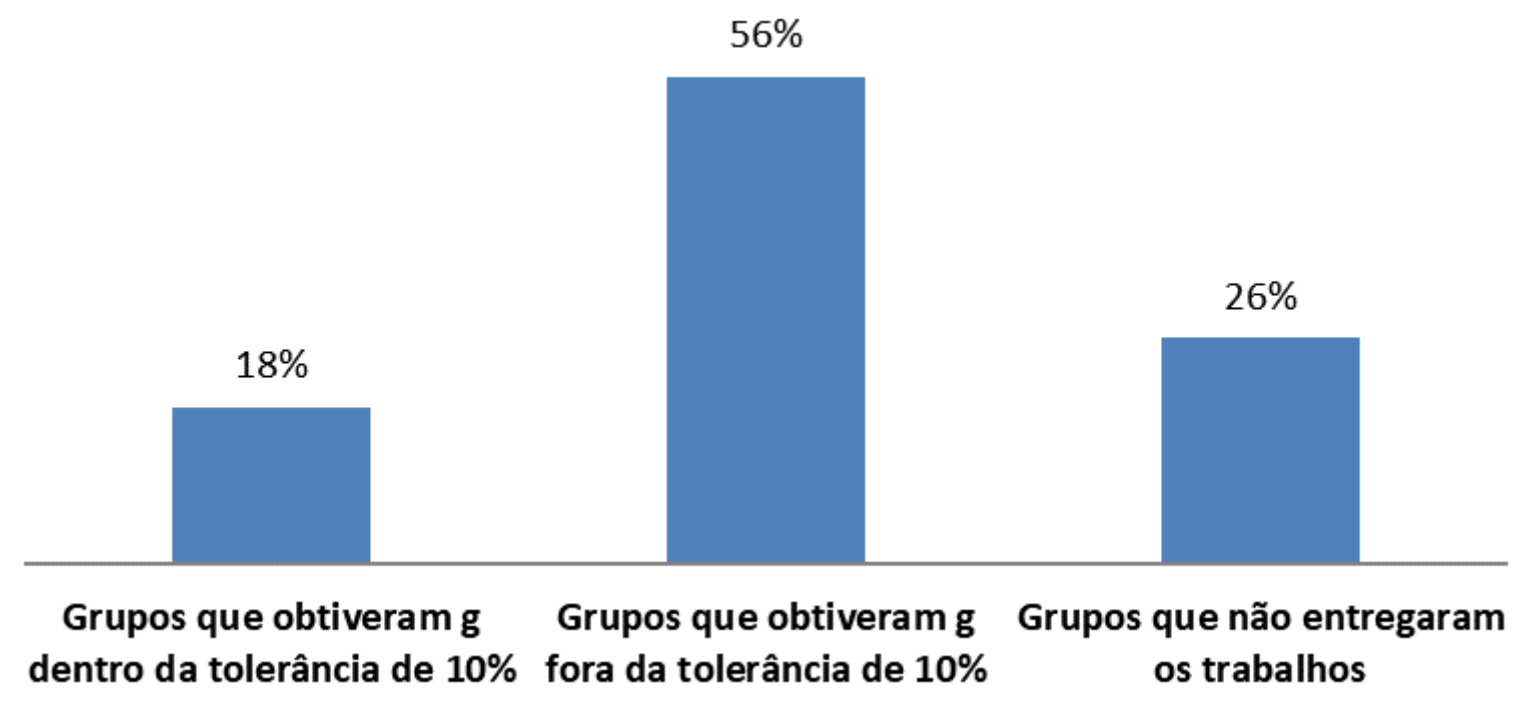

Fonte: Autores, 2018. 
Figura 2 - Resultados obtidos considerando todas as turmas, segundo o Procedimento 2 (experimentos mediados pelo Tracker)

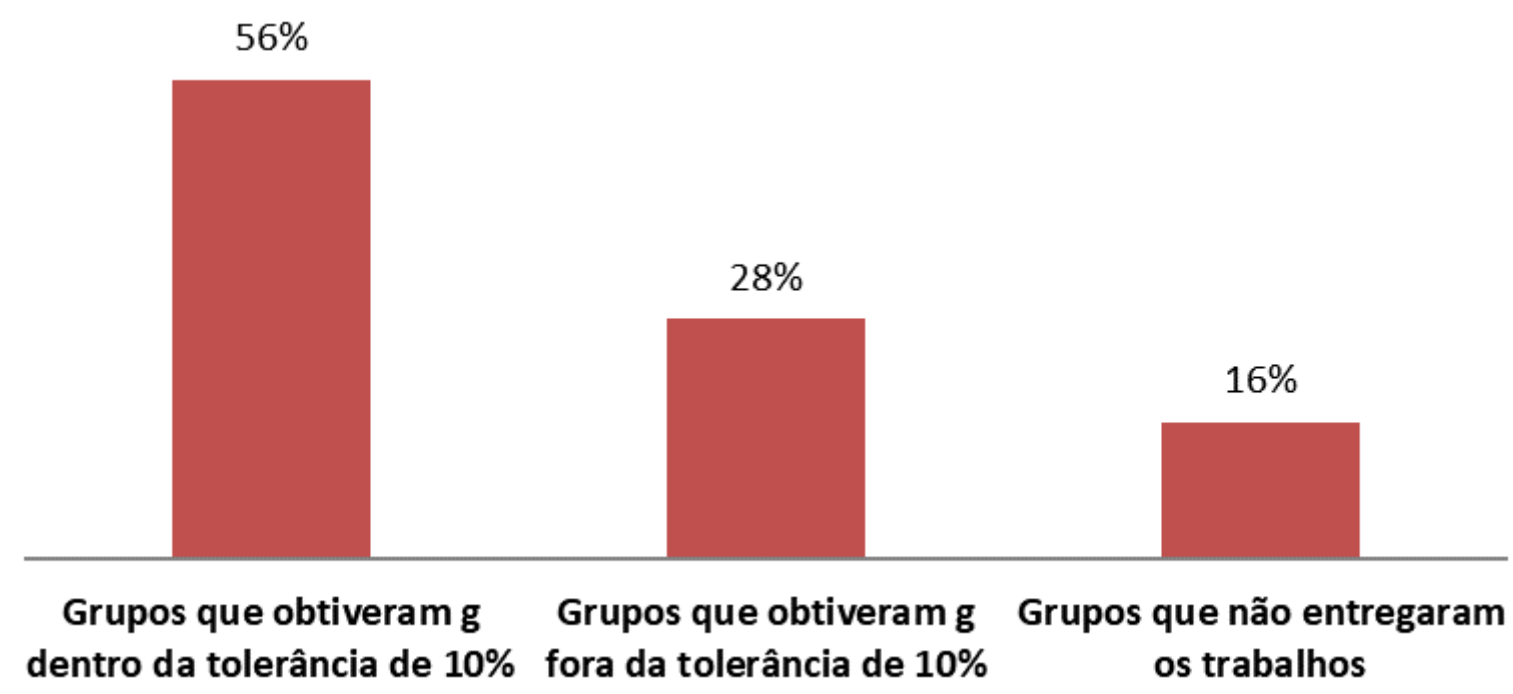

Fonte: Autores, 2018.

Como pode ser observado na Figura 1, 56\% das equipes obtiveram valores de $g$ fora da tolerância de $10 \%$. Nesse caso, os estudantes haviam solto objetos em queda livre de alturas diferentes ( $2 \mathrm{~m}$ e $2,5 \mathrm{~m}$ ) e a maioria não conseguiu obter um mesmo valor de $g$ para as duas alturas distintas. Além disso, todas as equipes questionaram os resultados, por já terem conhecimento, a partir das informações dos livros didáticos, do valor aproximadamente constante de $g$ na superfície terrestre.

A análise das respostas às seis perguntas revela percepções interessantes. Por exemplo, com respeito à Questão 1 (As duas experiências permitem obter valores próximos para $g$ ?), as anotações do professor no diário de bordo revelam que muitos estudantes ficaram surpresos com o fato de que, em alguns experimentos, o tempo de queda medido foi maior para a altura menor (o que, de fato, revela uma dificuldade no acionamento manual dos cronômetros). Seguem algumas falas representativas:

Aluno D: O tempo da altura maior é menor porque a bola desce mais rápido?

Aluno J: Como que na altura maior o tempo deu menor que na altura menor?

Aluno V: A o valor da conta aqui deu mais alto na altura maior.

Esses comentários denotam a surpresa dos estudantes com relação ao esperado (o tempo deveria ser menor para a altura menor). Destarte o processo proporcionou que os estudantes passassem a refletir sobre as possíveis causas para as discrepâncias, o que vai ao encontro da metodologia do laboratório não-estruturado (PINHO, 2004).

No que tange à Questão 2 (Foi relativamente fácil acionar e parar o cronômetro nos exatos momentos que a bola inicia a queda e toca o solo?), os relatos dos alunos inicialmente apontavam a facilidade de realizar os experimentos. Porém, ao se depararem com os resultados majoritariamente discrepantes, voltaram-se para a identificação de possíveis falhas na execução experimental, pois, além de conhecido o valor de $g$, a intervenção feita pelo professor, com uma abordagem histórica das discussões de Galileu Galilei sobre a queda livre, legou aos mesmos 
a percepção de que o experimento "deveria dar certo". Alguns diálogos entre o professor e os grupos são transcritos abaixo:

Aluno G: Professor, por que tem gente que dá uns tempos bem iguais e outras dá bem diferente?

Professor: Tem como todo mundo apertar o botão sempre na mesma hora? Todo mundo tem a mesma habilidade?

Aluno G: Não né!

Aluno R: Professor, não tem como dar a mesma coisa sempre porque a gente não consegue apertar o botão sempre na mesma hora e quando você joga a bola a altura nem sempre é a mesma.

Professor: Mas não foram todas abandonadas de dois metros?

Aluno R: É, mas às vezes a mão fica um pouquinho mais levantada.

Nos relatos acima, as equipes passam a identificar o "fator humano", na intervenção deles no processo de medição, representado no apertar dos botões do cronômetro e no posicionamento do objeto a ser solto. Como é difícil garantir precisão e repetição para os diferentes lançamentos, estariam aí, portanto, as discrepâncias com relação ao valor então teórico e conhecido de $g$. Isso levantou discussões adicionais, como, no método científico experimental utilizado na Física, a reprodutibilidade ser um fator determinante. Por isso, a Questão 3 (Qual foi erro percentual em relação a $g$ encontrado nesse procedimento?) conduziu ao questionamento de "o que poderia ser feito", para melhorar os resultados. Daí surgiu a oportunidade para o professor sugerir uma mediação tecnológica (a videoanálise, por meio do Tracker) como forma de contornar o problema. Assim justifica-se a realização do Procedimento 2. De fato, como pode ser observado na Figura 2, houve um aumento significativo dos grupos que obtiveram valores de $g$ mais precisos, justamente por causa do uso da videoanálise, o que serve de embasamento para as respostas à Questão 4 (Qual foi o valor da aceleração encontrada usando o software Tracker?)

No caso da Questão 5 (Os resultados encontrados usando o Tracker foram diferentes dos resultados encontrados no Procedimento 1?), conforme apresentado na comparação dos dois gráficos (Figuras 1 e 2), as próprias equipes, agora, passaram a refletir sobre a melhoria dos resultados, convergindo para a relevância da mediação do experimento pela utilização das TIC's (no caso, o Tracker).

A partir da Questão 6 (A aceleração usando o Tracker deu um valor próximo a $9,8 \mathrm{~m} / \mathrm{s}^{2}$ ? Qual foi o erro percentual?), a constatação positiva a essa resposta, fez com que as equipes passassem a explorar com mais interesse a utilização do Tracker, conforme podemos observar nas seguintes transcrições: 
Aluno L: Usar o Tracker foi muito legal porque foi possível a gente fazer algo diferente na escola, fazer experiências e ver algo diferente.

Aluno A: Foi legal mexer no Tracker principalmente depois da aula porque foi divertido, pudemos mexer com brinquedos e percebi que posso medir várias coisas.

Aluno N: Faz a aula ficar legal e faz a gente usar coisas diferentes pra deixar as aulas menos chatas.

A citação e o apelo ao "fazer diferente", por sua vez, incentiva a "curiosidade epistemológica”, característica importante na Pedagogia Freireana (FREIRE, 1996). É nesse sentido que se alimenta a autonomia dos estudantes: "fazer experiências e ver algo diferente". Eles também perceberam como uma ferramenta de mediação tecnológica pode levar a resultados mais precisos do que procedimentos manuais, além de permitir ver a evolução temporal das grandezas físicas. Desse modo, podemos constatar evidências de que a mediação tecnológica nesse processo de ensino e aprendizagem, em uma metodologia com laboratório não estruturado, videoanálise em contraste com procedimentos manuais, permitiram que fossem contempladas tanto a dimensão simbólica (os questionamentos dos alunos com relação às discrepâncias do valor já conhecido de $g$, a busca pelas fontes de erros) e também material (a identificação, pelas equipes, das vantagens para a aprendizagem em utilizar corretamente uma TIC, o Tracker, e as possibilidades abertas pela mesma), o que corrobora tanto na diminuição da sua vulnerabilidade social (ABRAMOVAY et al., 2002) como no reforço à necessidade de inovações pedagógicas pelos professores na mediação dos processos de ensino e aprendizagem. Nesse caso, além da mediação do saber (a aceleração da gravidade terrestre) é necessário formar os alunos na mediação tecnológica capaz de expandir as suas percepções, tanto do fenômeno em si, como da natureza ao seu redor (AVIDOV-UNGAR; FORKOSH-BARUCH, 2018).

A análise do diário de campo permite ainda fazer outras observações relevantes. Por exemplo, no Procedimento 1, os estudantes mediam o tempo de queda $(t)$, a partir de uma altura $(h)$ dada e, por meio da expressão $h=\frac{1}{2} g t^{2}$, calculavam o valor de $g$ diretamente "pela fórmula". Nesse contexto, a utilização do Tracker permitiu a obtenção de gráficos $(h x t)$ e, com isto, os estudantes puderam "provar" que o movimento é, de fato, representado por uma parábola, de modo que o cálculo da aceleração da gravidade foi mais do que uma simples "aplicação de fórmula", em outra indicação de que as atividades experimentais mediadas pela videoanálise permitem ampliar as possibilidades de ensino. Além disso, ficou evidente que os estudantes se sentiram mais estimulados a estudar o assunto um função do uso da videoanálise, na comparação com situações passadas em que o tema havia sido abordado sem o auxílio do Tracker. O processo também permitiu a diversos estudantes um contato mais aprofundado com a tecnologia (o computador, as câmeras, o software), de maneira a alargar seus horizontes com relação ao uso circunstanciado, consciente e crítico da mesma.

Outro aspecto a ser destacado é o trabalho em equipe, estimulado pelas atividades propostas e pelo interesse despertado pela tecnologia utilizada. Nesse sentido, o fato de o Tracker permitir aos estudantes a realização de experimentos também fora da sala de aula, abre perspectivas de trabalho e estudos interessantes dada a realidade da escola em questão. Assim, mesmo 
com a ausência do laboratório didático, foi possível, por meio do uso do Tracker, elaborar e apresentar atividades experimentais relevantes aos estudantes.

\section{CONSIDERAÇÕES FINAIS}

O uso do Tracker no ensino médio provocou quebras de rotina no ambiente escolar, proporcionando aos alunos executarem experimentos significativos, obter resultados numéricos, e desempenhar diversas atitudes relevantes para o processo de aprendizagem.

Com a realização do projeto na escola, percebe-se claramente que a utilização do Tracker permitiu aos estudantes o contato com atividades que, até então, não eram realizadas em sala de aula, provocando maior envolvimento e despertando mais motivação por parte dos alunos, aspecto também verificado por Bezerra Junior e colaboradores (2012) e por Wrasse e colaboradores (2014). Essa relação entre o Tracker e arranjos experimentais acessíveis também foi relatada por Silva (2018). Nesse sentido, houve a introdução de um elemento importante no processo de aprendizagem: as atividades experimentais. Segundo Phommarach e colaboradores (2012), é justamente por meio dessas atividades que os estudantes relacionam a teoria com o movimento real e, assim, constroem um entendimento mais completo.

A maioria dos alunos realizou todas as atividades sugeridas, num claro indício de que a utilização do Tracker serviu de desafio e motivação adicional à participação ativa dos estudantes. Constatou-se que, na maioria dos trabalhos realizados, os alunos conseguiram medir $g$ de modo efetivo e preciso, tendo em vista os critérios adotados, bem como notar diferenças fundamentais entre a medição manual e a mediada pela videoanálise (Procedimentos 1 e 2). De fato, Pinho Alves argumenta que, por meio de atividades experimentais:

A participação ativa do aluno em situação de investigação real, proposta na forma de desafio, o instigará na busca de uma resposta correta, entendendo o correto como exercício de um procedimento que se baseia em uma hipótese teórica para a resolução de um problema científico (PINHO, 2000, p. 257).

Por ser um software livre e não exigir o uso de computadores potentes, o Tracker apresenta facilidade de acesso, uma característica fundamental quando se almeja implementar novas tecnologias em sala de aula. Além disso, por haver amplo material de divulgação e manuais em português, bem como diversos trabalhos na literatura exemplificando seu uso, o Tracker é compatível com a realidade escolar brasileira. A despeito de ter sido inicialmente concebido em língua inglesa, sua disponibilidade em língua portuguesa o torna passível de ser usado em aulas de Física, em particular, e de ciências, em geral, desde o nono ano do ensino fundamental até o nível superior. Por isso, este projeto também ilustra uma iniciativa concreta de suporte ao desenvolvimento profissional do professor, à luz de uma novidade pedagógica (a videoanálise com o Tracker), o que constitui um desafio na "era da informação" (AVIDOV-UNGAR; FORKOSH-BARUCH, 2018). 
Neste trabalho, fruto de um projeto de mestrado profissional em Ensino, são apresentadas evidências de que é possível realizar atividades experimentais de Física mesmo em escolas situadas em áreas de vulnerabilidade social. O trabalho é potencializado pelo uso da videoanálise, por meio do programa Tracker. Esse desponta como relevante tecnologia e de grande capacidade para utilização em sala de aula, especialmente em escolas nas quais não há maiores recursos de laboratório. O potencial do uso do Tracker também se verifica no que tange à facilidade de aprendizado e à rapidez com que pode ser incorporado às aulas, com ênfase para o contexto da escola pública. Nesse sentido, destaca-se que o trabalho aqui descrito foi realizado durante um semestre letivo, nas condições reais da escola, envolvendo mais de uma centena de estudantes oriundos de classes socialmente desfavorecidas. Tendo em vista a experiência vivida, pode-se afirmar que professores e estudantes vivenciaram momentos conjugando aprendizagem, interação, intercomunicação, criticidade e liberdade. $\mathrm{O}$ empenho e a dedicação do professor-pesquisador e dos estudantes demonstram que a escola pode ser iluminada desde dentro e, assim, “os homens se libertam em comunhão” (FREIRE, 1987, p. 29). 


\section{REFERÊNCIAS}

ABRAMOVAY, Miriam et al. Juventude, violência e vulnerabilidade social na América Latina: desafios para políticas públicas, UNESCO Brasilia/Interamerican Development Bank, 2002.

ARAUJO, Ives Solano; VEIT, Eliane Angela; MOREIRA, Marco Antonio. Atividades de modelagem computacional no auxílio à interpretação de gráficos da cinemática. Revista brasileira de ensino de física, SciELO Brasil, v. 26, n. 2, p. 179-184, abr./jun. 2004.

AVIDOV-UNGAR, Orit; FORKOSH-BARUCH, Alona. Professional identity of teacher educators in the digital era in light of demands of pedagogical innovation. Teaching and Teacher Education, Elsevier, v. 73, p. 183-191, 2018.

BEZERRA, Arandi Ginane et al. Uma abordagem didática do experimento de Millikan utilizando videoanálise. Acta Scientiae, v. 17, n. 3, 2015.

BEZERRA, Arandi Ginane et al. Tecnologias livres e ensino de física: uma experiência na UTFPR. In: XVIII Simpósio Nacional de Ensino de Física. [S.1.: s.n.], 2009. v. 17.

BEZERRA, Arandi Ginane et al. Videoanálise com o software livre Tracker no laboratório didático de física: movimento parabólico e segunda lei de Newton. Caderno Brasileiro de Ensino de Física, v. 29, p. 469-490, 2012.

BONATO, Jacopo et al. Using high speed smartphone cameras and video analysis techniques to teach mechanical wave physics. Physics Education, IOP Publishing, v. 52, n. 4, p. 045017, 2017.

BORGES, Antônio Tarciso. Novos rumos para o laboratório escolar de ciências. Caderno Brasileiro de Ensino de Física, v. 19, n. 3, p. 291-313, 2002.

BRASIL, Ministério da Educação. Planejando a Próxima Década. Conhecendo as 20 Metas do Plano Nacional de Educação. [S.1.]: Brasília: Ministério da Educação, 2014.

BROWN, Douglas; COX, Anne J. Innovative uses of video analysis. The Physics Teacher, AAPT, v. 47, n. 3, p. 145-150, 2009.

BRYAN, JA. Investigating the conservation of mechanical energy using video analysis: four cases. Physics Education, IOP Publishing, v. 45, n. 1, p. 50, 2010.

FREIRE, Paulo. Pedagogia do Oprimido. 17ª [S.l.: s.n.], 1987. v. 3. 343-348 p.

FREIRE, Paulo. Pedagogia da Autonomia: saberes necessários à prática educativa. [S.1.: s.n.], 1996.

FREIRE, Paulo. Educação como prática da liberdade. [S.1.]: Ed. Rio de Janeiro: Paz e Terra, 2011.

GERALDO, Antonio Carlos Hidalgo. Didática de ciências naturais na perspectiva históricocrítica. [S.1.: s.n.], 2009. 171 p.

LENZ, Jorge Alberto; FILHO, Nestor Cortez Saavedra; JR, Arandi Ginane Bezerra. Utilização de tic para o estudo do movimento: alguns experimentos didáticos com o software Tracker. Abakós, v. 2, n. 2, p. 24-34, 2014. 
MÜTZENBERG, Luiz André. Trabalhos trimestrais: pequenos projetos de pesquisa no ensino de Física, Porto Alegre: IF-UFRGS, v. 16, n. 6, 2005.

PARANÁ. Diretrizes Curriculares da Educação Básica. Física., Curitiba: Secretaria de Estado da Educação, 2018.

PEDRINI, Alexandre; COSTA, Érika Andrade; GHILARDI, Natalia. Percepção ambiental de crianças e pré-adolescentes em vulnerabilidade social para projetos de educação ambiental. Ciência \& educação, SciELO Brasil, v. 16, n. 1, p. 163-179, 2010.

PHOMMARACH, S; WATTANAKASIWICH, P; JOHNSTON, I. Video analysis of rolling cylinders. Physics Education, IOP Publishing, v. 47, n. 2, p. 189, 2012.

PINHO, José de. Atividades experimentais: do método à prática construtivista. 2000. Tese (Doutorado) - Universidade Federal de Santa Catarina, Florianópolis.

PINHO, José de. Regras da transposição didática aplicadas ao laboratório didático. Caderno brasileiro de ensino de Física, v. 17, n. 2, p. 174-188, 2004.

SAAVEDRA, Nestor Cortez; LENZ, Jorge Alberto; JR, Arandi Ginane Bezerra. Utilização da videoanálise para o estudo do movimento circular e a construção do conceito de aceleração centrípeta. Acta Scientiae, v. 18, n. 3, 2016.

SAAVEDRA, Nestor Cortez et al. A videoanálise como mediadora da modelagem científica no ensino de mecânica. Revista Brasileira de Ensino de Ciência e Tecnologia, v. 10, n. 3, 2017.

SILVA, ES. Estudo da relação entre o movimento circular uniforme e o movimento harmônico simples utilizando a videoanálise de uma roda de bicicleta. Caderno Brasileiro de Ensino de Física, v. 40, n. 2, 2018.

SILVA, Erick dos Santos; LIMA, André Rubens. Estudo da vazão de uma fonte por meio da videoanálise: uma proposta utilizando recipientes na forma de prismas regulares. Caderno Brasileiro de Ensino de Física, Universidade Federal de Santa Catarina (UFSC), v. 34, n. 3, p. 903-911, 2017.

SIRISATHITKUL, $\mathrm{C}$ et al. Digital video analysis of falling objects in air and liquid using Tracker. Revista Brasileira de Ensino de Física, SciELO Brasil, v. 35, n. 1, p. 1-6, 2013.

STORI, Airton et al. Uma iniciativa (para nós importante) na perspectiva da melhoria das condições de ensino-aprendizagem de física na escola pública do Paraná. In: SIMPÓSIO NACIONAL DE ENSINO DE FÍSICA, XVIII. [S.1.: s.n.], 2009.

TRACKER. TRACKER. 2018. Disponível em: <http://trackerbrasil.ct.utfpr.edu.br/>. Acesso em: 28 maio 2018.

TRACKERBRASIL. TRACKERBRASIL. 2018. Disponível em: <http://trackerbrasil.ct.utfpr. edu.br/>. Acesso em: 28 maio 2018.

VEIT, Eliane Angela; ARAUJO, Ives Solano; HAAG, Rafael. Por que e como introduzir a aquisição automática de dados no laboratório didático de física? Física na escola, v. 6, n. 1, p. 69-74, maio 2005.

VICENTE, Kim. Homens e máquinas. [S.1.]: Ediouro Publicações, 2005.

WRASSE, Ana Cláudia et al. Investigando o impulso em crash tests utilizando vídeo-análise. Revista Brasileira de Ensino de Física, v. 36, n. 1, p. 1501, 2014. 